\title{
Trichromatic Enhanced Dynamic Color Screening on the PDI Check Nintendo 3DS Game
}

\author{
Andrew Arnold (ID) \\ Kyle Smith ${ }^{2}$ \\ Aaron Molina ${ }^{2}$ \\ Alex Damarjian ${ }^{2}$ \\ Tarah Desatoff ${ }^{3}$ \\ Robert Arnold (D) ${ }^{4}$ \\ 'Pacific Northwest University College of \\ Osteopathic Medicine, Yakima, WA, USA; \\ ${ }^{2}$ PDI CHECK, Anchorage, AK, USA; \\ ${ }^{3}$ Optometry Department, South Central \\ Foundation, Wasilla, AK, USA; ${ }^{4}$ Alaska \\ Blind Child Discovery, Alaska Children's \\ EYE \& Strabismus, Anchorage, AK, USA
}

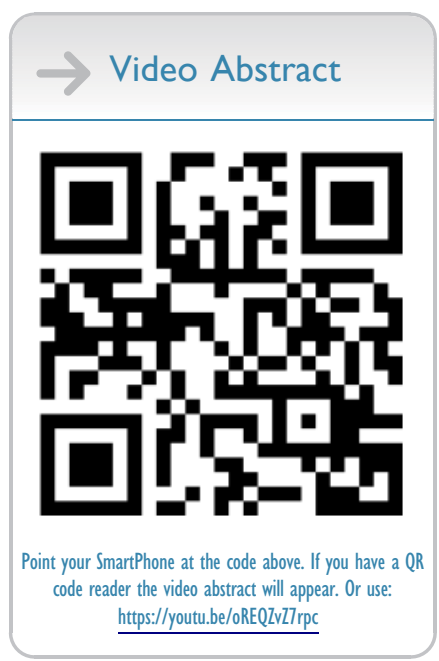

Correspondence: Robert Arnold Alaska Children's EYE \& Strabismus, 3500 Latouche \#280, Anchorage, AK, 99508, USA

Tel + | 907561-1917

$\mathrm{Fax}+$ I 907563-5373

Email eyedoc@alaska.net
Introduction: Classification of color deficiency has required substantial time and expense with the static Farnsworth-Munsell and Innova Rabin tests. Therefore, dynamic color tests were developed for the Nintendo 3DS.

Methods: Fifteen color deficient patients and 17 age-matched normals performed Rabin color test in addition to PDI Check dynamic color games resembling Farnsworth-Munsell presentation (version 0.2.8) and 3-color iso-luminance gray (version 0.2.13).

Results: Tests of red, green and blue cone-deficient with the v0.2.8 had sensitivity/specificity/PPV of $92 \% / 86 \% / 92 \%$ protanopes, $78 \% / 90 \% / 88 \%$ deutanopes and $87 \% / 50 \% / 93 \%$ tritanopes. Version 0.2 .13 had sens/spec/PPV of 78\%/83\%/78\% red-cone, $100 \% / 85 \% / 80 \%$ green cone and $67 \% / 78 \% / 33 \%$ blue cone. Corresponding IntraClass Correlation (ICC) utilizing v0.2.8 were red-cone $0.22(-0.02-0.60)$, green-cone $0.34(-0.10-0.67)$ and blue-cone 0.38 $(0.12-0.75)$. ICC for v0.2.13 was higher with protanope $0.62(-0.07-0.87)$, deuteranope 0.64 $(-0.09-0.88)$ and tritanope $0.31(-0.07-0.70)$. The PDI Check color game took 65 seconds compared to 197 seconds for Innova Rabin.

Conclusion: The PDI Check color game quickly identifies patients with inherited color deficiencies.

Keywords: color blindness, deuteranomaly, protanomaly, Farnsworth-Munsell, Rabin color cone test, dynamic, vision screening

\section{Plain Language Summary}

In addition to visual acuity, peripheral vision and depth perception, human eyes can detect a range of color. Three different sets of cones in the retina sense red, green and blue tones to provide a full spectrum. Individuals, mainly males, with inherited color blindness have decreased numbers or performance of either their green, their red or rarely their blue cones. Formal tests to identify and quantify color blindness take substantial time and money. An inexpensive game on the Nintendo 3DS console presents certain colored objects to either right or left eye gradually changing from subtle to obvious allowing quick identification of the three main types of color blindness.

\section{Introduction}

Accurate characterization of color defects is important in the diagnosis and management of inherited and acquired retinal and neuro-ophthalmic conditions. Adult and pre-literate matching cards are often used clinically, however more complex tests are required for detailed diagnosis and quantification of color deficiency. ${ }^{1}$ Many tests are expensive and require significant time, understanding ${ }^{2}$ and cooperation. Smartphone presentation can substitute for flip-book Ishihara color plates. ${ }^{3}$ 
Table I Compared Color Vision Tests on the PDI Check Game Against the Innova Rabin Trichromatic Standard Test

\begin{tabular}{|l|l|l|l|l|l|l|l|l|l|l|l|}
\hline Version & & ICC & Up ICC & Low ICC & Mean Diff & Low & Up & SE & Sensitivity & Specificity & PPV \\
\hline 0.2 .8 & F-M red & 0.22 & -0.02 & 0.6 & 7.66 & -48.9 & 64.2 & 6.6 & $92 \%$ & $86 \%$ & $92 \%$ \\
& F-M green & 0.34 & -0.1 & 0.67 & 8.89 & -51.6 & 69.4 & 7.1 & $78 \%$ & $90 \%$ & $88 \%$ \\
& F-M blue & 0.38 & 0.12 & 0.75 & -33.7 & -77.4 & 10.1 & 5.3 & $87 \%$ & $50 \%$ & $93 \%$ \\
\hline \multirow{2}{*}{0.2 .13} & Iso-gray red & 0.62 & -0.07 & 0.87 & $-27 \%$ & $-81 \%$ & $28 \%$ & $4 \%$ & $78 \%$ & $83 \%$ & $78 \%$ \\
& Iso-gray green & 0.64 & -0.09 & 0.88 & $28 \%$ & $-77 \%$ & $21 \%$ & $4 \%$ & $100 \%$ & $85 \%$ & $80 \%$ \\
& Iso-gray blue & 0.31 & -0.07 & 0.7 & $-22 \%$ & $-40 \%$ & $-4 \%$ & $2 \%$ & $67 \%$ & $78 \%$ & $33 \%$ \\
\hline
\end{tabular}

Abbreviations: ICC, intraclass correlation; F-M, Farnsworth-Munsell.

Utilizing the autostereoscopic barrier screen of the Nintendo 3DS XL console, near vision screening testing games have been developed. ${ }^{4}$ Near monocular visual acuity, stereopsis and color vision can be screened in normal military staff and also in remote, non-English speaking villagers. ${ }^{5}$ PDI Check correlates well with conventional near vision tests and helps identify ocular suppression both through stereo deficiency, but also with autostereoscopically presented, rivalry near optotypes. ${ }^{6}$ Champion shotgun shooters demonstrated extraordinary red-cone and blue cone detection with PDI Check compared to age-matched normal subjects. ${ }^{7}$

We undertook this study to analyze two types of dynamic, quick trichromatic separated color tests on the PDI Check and then compare them with industry standard, static, calibrated, computer delivered Innova Rabin system. ${ }^{1,8}$

\section{Methods}

This study has IRB approval through Pacific University [109-17; 1098158-5]. It complies with the Declarations of Helsinki and the Health Insurance Portability and Accountability Act. Patients and/or their guardians provided written informed consent. De-identified data can be found: http://www.abcd-vision.org/references/Color\% 20PDI\%20Rabin.pdf.

Color deficient individuals were identified through Ishihara testing during eye examinations. Normal subjects were recruited from clinical and research staff. Each performed Innova Rabin's Cone Contrast color test ${ }^{8}$ following standard procedure monocularly with the non-tested eye patched.

PDI Check has two different dynamic color testing games; two different dynamic color tests were programmed for the Nintendo 3DS XL. One ("FM," version 0.2.8) presents four forced choice identical discs on the upper screen starting at the cone confusion regions of an FM 100 test, then one random quadrant gradually deviates around the spectrum for the subject to identify by clicking the lower screen. The second type of test ("gray disc," version 0.2.13) starts with four iso-luminance gray discs against a neutral gray background. Then the pixels directed at one eye, in one random quadrant transform into a gradually intensifying teal, pink or a purple color for the subject to select as soon as the difference is perceived. Some subjects performed comparison of both PDI Check color versions. The Nintendo 3DS console automatically adjusts background screen luminance to an aesthetically pleasing viewing level. The PDI Check game on Nintendo 3DS and the Innova Rabin tests were viewed from $30 \mathrm{~cm}$.

Given a mean of 95 and standard deviation of 10 , the sample size to detect a difference of 15 given alpha 0.05 and Power 0.80 is 7 .

\section{Results}

Fifteen color deficient individuals were identified through Ishihara testing during comprehensive eye examinations. Ages ranged from 7 to 50 years. According to Innova Rabin scores, the hue was predominantly red deficient in 6 , green deficient in 8 and blue deficient in one. Thirteen of the fifteen color deficient were males. Seventeen normal individuals aged 11 to 60 served as controls of which 7 were males.

All subjects scored at least 20/25 on near testing. The mean and standard deviation combined right and left color score in Innova Rabin for normals was 97 \pm 1 (range 96-98) compared to $81.4 \pm 9$ (range 61-88) for PDI Check. The corresponding values for any color deficiency Innova Rabin was $65 \pm 10$ (range 47-77) and for PDI Check 66 \pm 16 (range 31-80). For $\mathrm{n}=7$ green deficient, Innova Rabin was $67 \pm 8$ (range 58-77) and for PDI Check 68 \pm 13 (range 41-80).

The time to perform patched Innova Rabin on both eyes averaged 197 seconds (range 162 to 260 seconds) 
while time to complete un-patched, monocular PDI Check dynamic gray-game for both eyes averaged 65 seconds (range 40-120 seconds).

The test re-Test reliability for version 0.2 .8 color was 54 \pm 7 for red, $60 \pm 6$ for green and $63 \pm 7$ for blue; essentially the deviation was $10 \%$ of the mean. In comparison, PDI stereo can perform with $3 \%$ deviation compared to the mean.

Bland Altman plots for normals and color deficient with version 0.2.13 are shown in Figure 1. The mean differences for normals was $16 \pm 3$ (SEM) with PDI Check normals reporting the lower value. Corresponding IntraClass Correlation (ICC) utilizing v0.2.8 were red-cone 0.22 $(-0.02-0.60)$, green-cone $0.34(-0.10-0.67)$ and blue-cone
$0.38(0.12-0.75$; Table 1)Table 1. ICC for v0.2.13 were higher with protanope $0.62(-0.07-0.87)$, deuteranope 0.64 $(-0.09-0.88)$.

Tests of red, green and blue cone-deficient with the v0.2.8 had sensitivity/specificity/PPV of $92 \% / 86 \% / 92 \%$ for protanopes, $78 \% / 90 \% / 88 \%$ deutanopes and $87 \%$ / $50 \% / 93 \%$ for the tritanope. Version 0.2 .13 had sensitivity/specificity/PPV of $78 \% / 83 \% / 78 \%$ red-cone and $100 \% /$ $85 \% / 80 \%$ green cone.

\section{Discussion}

After gradual recruitment from a pediatric eye clinic, patients with inherited color deficiency and age-matched normal

\section{Normal Color}

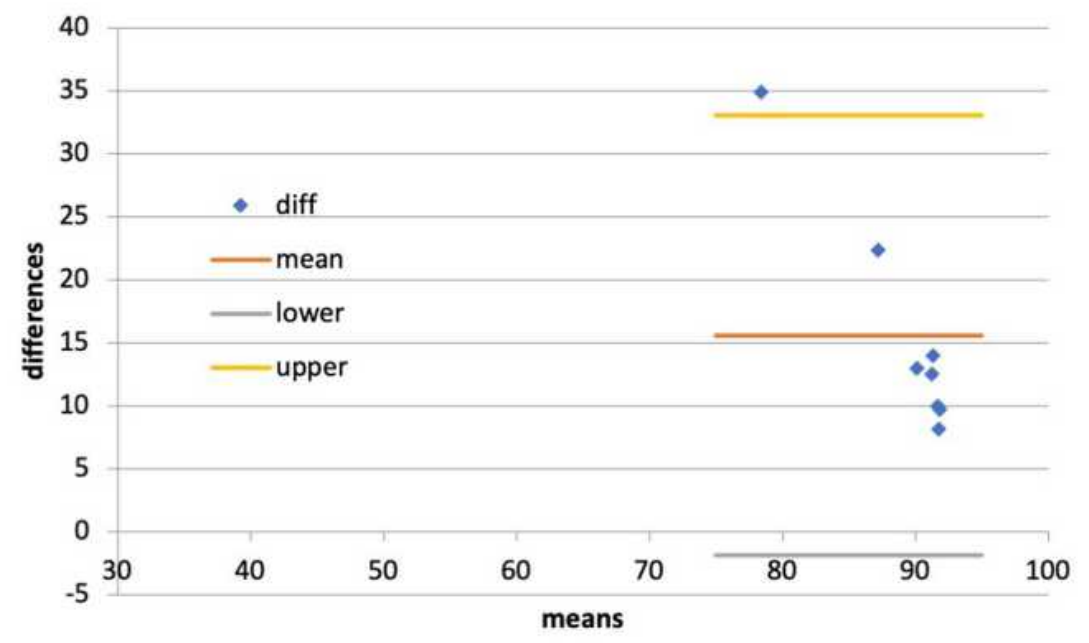

Color Deficient

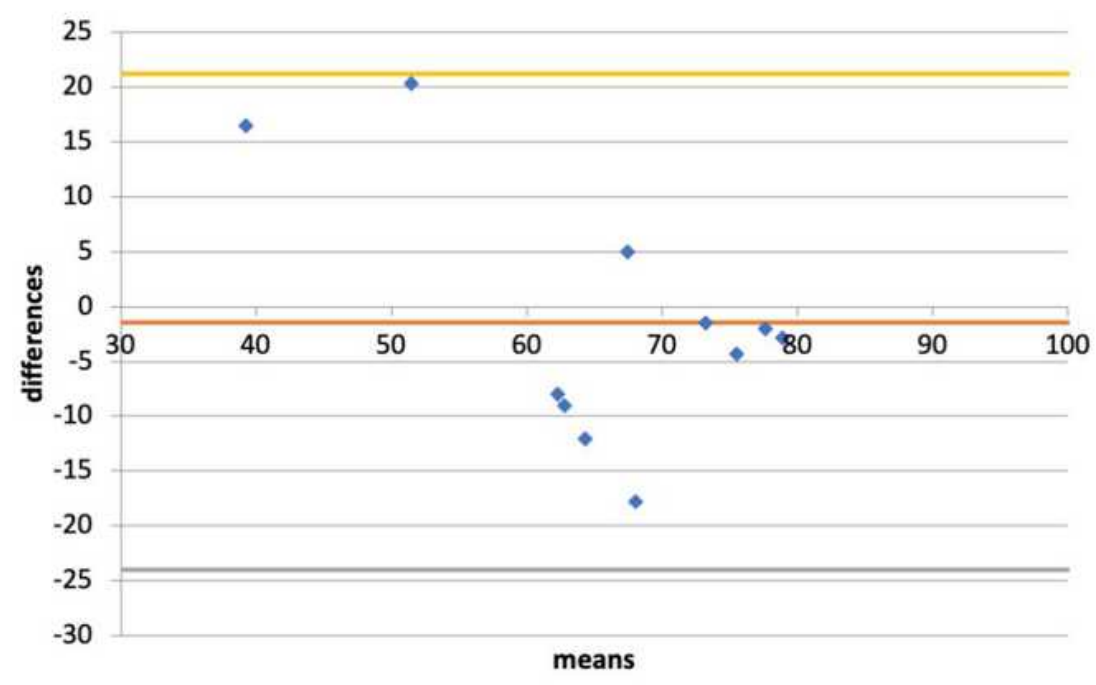

Figure I Bland Altman analysis of color scores comparing PDI Check gray disc with Innova Rabin trichromatic scores averaged with both eyes for age-matched normal and patients with inherited color deficiencies. 
subjects had compared digital trichromatic evaluation on the same day. Each had industry- and US Military standard INNOVA Rabin computerized, timed static color quantification with non-tested eye patched compared to non-patched, dynamic, autostereoscopic monocular presentation on a portable, Nintendo 3DS XL game console. There was a good correlation and the dynamic presentation was quicker. Speed was not the issue when multiple digital color tests were compared in 68 color defective individuals without colornormal controls. ${ }^{9}$ Insufficient time can be an issue with the D15 type color tests. ${ }^{10}$

A limitation of this study was relatively small sample size. It is not simple to collect large numbers of color deficient individuals due to the relative rarity of the condition. ${ }^{5}$ We did not yet include patients with acquired color defects. We defined color cone deficiency by Innova Rabin method that may not exactly represent FM 100 or anomaloscope. Not all our subjects were able to complete both PDI Check versions on the different test phases, but an advantage of our study was head-to-head comparison of two digital tests one the same day with identical lighting. The scores for normal color in PDI Check under-estimated Innova Rabin values therefore further mathematical modeling is underway. PDI Check continues to refine the output and presentation of the game to better provide useful clinical data. The autostereoscopic screen on the Nintendo 3DS XL allows monocular rapid screening for color defects in addition to monocular near dynamic acuity and stereopsis.

\section{Conclusion}

PDI Check in a quick, dynamic, forced-choice monocular presentation was able to quickly discriminate color deficient from normal vision individuals.

\section{Abbreviations}

Diff, difference; D-15, type of color quantifying test using 15 discs of different hue; F-M, Farnsworth-Munsell; ICC, intraclass correlation; PPV, positive predictive value; S.E., standard error; SEM, standard error of the mean; sens, sensitivity; spec, specificity; 3DS XL, model of autostereoscopic game console.

\section{Data Access}

De-identified data can be found: http://www.abcd-vision. org/references/Color\%20PDI\%20Rabin.pdf.

\section{Funding}

There is no funding to report.

\section{Disclosure}

Robert Arnold, Kyle Smith, Aaron Molina and Alex Damarjian are board members of PDI Check. Robert Arnold and Alex Damarjian have patent pending on autostereoscopic vision screening. Robert Arnold is also President of Glacier Medical Software and is coordinator of the Alaska Blind Child Discovery which has received discounted vision screen technology from several vendors. Robert Arnold reports nonfinancial support from PDI Check, during the conduct of the study; non-financial support from and being a board member of Glacier Medical Software, nonfinancial support from GoCheck Kids, PlusoptiX, Adaptica, and iScreen, and non-financial support from and being an investigator and protocol developer for PEDIG, outside the submitted work. Andrew Arnold and Tarah Desatoff report no financial conflicts. The authors report no other potential conflicts of interest for this work.

\section{References}

1. Fanlo Zarazaga A, Gutierrez Vasquez J, Pueyo Royo V. Review of the main colour vision clinical assessment tests. Arch Soc Esp Oftalmol. 2019;94(1):25-32. doi:10.1016/j.oftal.2018.08.006

2. Alexander KR. Color vision testing in young children: a review. $A m$ J Optom Physiol Opt. 1975;52(5):332-337. doi:10.1097/00006324197505000-00005

3. Ozgur OK, Emborgo TS, Vieyra MB, Huselid RF, Banik R. Validity and acceptance of color vision testing on smartphones. $J$ Neuroophthalmol. 2018;38(1):13-16. doi:10.1097/WNO.00000 00000000637

4. Smith KA, Damarjian AG, Molina A, Arnold RW. Calibrated measurement of acuity, color and stereopsis on a Nintendo 3DS game console. Clin Optom (Auckl). 2019;11:47-55. doi:10.2147/OPTO.S199992

5. Martin SJ, Rowe KS, Hser N, et al. Compared near vision testing with the Nintendo 3DS PDI check game on the Thai-Burma border. Asia Pac J Ophthalmol (Phila). 2019;8(4):330-334. doi:10.1097/ APO.0000000000000251

6. Smith KA, Arnold AW, Sprano JH, Arnold SL, Arnold RW. Performance of a quick screening version of Nintendo 3DS "PDI Check" game on patients with ocular suppression. J Pediatr Ophthalmol Strabismus. 2019;56(4):234-237. doi:10.3928/ 01913913-20190502-01

7. Brown SP, Rue CM, Smith KA, Arnold RW. Extraordinary dynamic near vision in champion shotgun shooters; PDI Check evaluation of stereo and color without floor effect. Clin Ophthalmol. 2021;15:575-581. doi:10.2147/OPTH.S298234

8. Chacon A, Rabin J, Yu D, Johnston S, Bradshaw T. Quantification of color vision using a tablet display. Aerosp Med Hum Perform. 2015;86(1):56-58. doi:10.3357/AMHP.4045.2015

9. Almustanyir A, Hovis J, Glaholt MG. Predicting the Farnsworth-Munsell D15 and Holmes-Wright-A lantern outcomes with computer-based color vision tests. J Opt Soc Am a Opt Image Sci Vis. 2020;37(4):A1-A10. doi:10.1364/JOSAA.381305

10. Dain SJ, Atchison DA, Hovis JK. Limitations and precautions in the use of the Farnsworth-Munsell Dichotomous D-15 test. Optom Vis Sci. 2019;96(9):695-705. doi:10.1097/OPX.0000000000001420 


\section{Publish your work in this journal}

Clinical Optometry is an international, peer-reviewed, open access journal publishing original research, basic science, clinical and epidemiological studies, reviews and evaluations on clinical optometry. All aspects of patient care are addressed within the journal as well as the practice of optometry including economic and business analyses. Basic and clinical research papers are published that cover

Submit your manuscript here: https://www.dovepress.com/clinical-optometry-journal all aspects of optics, refraction and its application to the theory and practice of optometry. The manuscript management system is completely online and includes a very quick and fair peer-review system, which is all easy to use. Visit http://www.dovepress.com/ testimonials.php to read real quotes from published authors. 